\title{
Mortality of adults with asthma: a prospective cohort study
}

\author{
Elisa Huovinen, Jaakko Kaprio, Erkki Vesterinen, Markku Koskenvuo
}

\begin{abstract}
Background - Few studies have been published on the overall survival of adult patients with asthma. A cohort study was performed to assess the mortality from all causes, from chronic obstructive pulmonary disease, and from lung cancer among adult asthmatic subjects.

Methods - A population of 31110 Finnish adult women and men, mostly twins, was studied to compare the 16 year mortality rates among asthmatic $(n=471)$ and nonasthmatic persons. A further 293 twin pairs, discordant for asthma, were also studied to determine whether the mortality of patients with asthma differs from that of their age matched siblings.

Results - Mortality from all causes was increased among asthmatic adults (age adjusted hazard ratios $1.49,95 \%$ CI 1.09 to 2.05 for men and $1.53,95 \%$ CI 1.10 to 2.13 for women), and mortality due to chronic obstructive pulmonary diseases was also significantly increased in asthmatic subjects. The risk of death due to lung cancer was increased in men with asthma (hazard ratio adjusted for smoking $3.19,95 \%$ CI 1.39 to 7.31 ). The risk ratios found among twins discordant for asthma corresponded to those found in the whole cohort.

Conclusions - Survival in adults with asthma is worse than in those without asthma. The excess deaths due to chronic obstructive pulmonary disease may explain some part of the increased mortality rates, but not all of it.

(Thorax 1997;52:49-54)
\end{abstract}

Department of Public Health, FIN-00014 University of Helsinki, Finland

E Huovinen

J Kaprio

Department of Allergic Diseases, Helsinki University Central Hospital, Finland

E Vesterinen

Department of Public Health, University of Turku, Finland

M Koskenvuo

Correspondence to: Dr J Kaprio.

Received 23 January 1996 Returned to authors

6 March 1996

Revised version received

16 April 1996

Accepted for publication

24 June 1996
Keywords: asthma, mortality, cohort study.

Data on the overall survival of adult patients with asthma are scanty since most studies report the effect only on specific asthma mortality. ${ }^{1}$ However, the available data on the survival of patients with asthma are inconsistent, with some studies showing no significant difference in survival in asthmatic cohorts, ${ }^{23}$ and others a raised mortality from all causes among asthmatic subjects. ${ }^{4-6}$ There are also conflicting reports on the risk of death due to cancer, ${ }^{7-9}$ with some studies even showing a reduced risk of cancer among asthmatic patients, ${ }^{1011}$ while case-control studies have indicated that patients with lung cancer are more likely to have a history of asthma than controls. ${ }^{12-14}$
Some of the inconsistency may have arisen from confounding since, although many studies have controlled for the effect of age, sex and smoking, ${ }^{2515}$ the effects of occupation ${ }^{15}$ and other lung diseases ${ }^{2}$ may also be important. We have studied mortality from all causes among persons with asthma in Finland in a population based cohort study, in addition to the specific risk of death due to asthma, chronic obstructive pulmonary disease, and lung cancer. Possible confounding due to smoking, social class, domestic animals and pets, other respiratory morbidity, and atopy have been taken into account.

\section{Methods}

STUDY POPULATION

The study population was based on the Finnish twin cohort which consists primarily of adult twin pairs, with both members alive in 1967 and born before 1958, as well as some unrelated individuals included because of the selection criteria used to form the cohort. ${ }^{16}$ Pairs of persons with the same date of birth, same surname at birth, same local community of birth, and same sex were identified from the Central Population Registry of Finland. A postal questionnaire was mailed in the autumn of 1975 with questions that covered twinship, medical history, symptoms, state of health, social factors, and psychological traits. The response rate of the questionnaire study was $89 \%$, yielding 31110 responses, 26533 from twins and 4577 from singletons. Twinship was determined from questionnaire responses and confirmed, when necessary, from birth records in local parish registers. Zygosity was determined by a validated questionnaire method. ${ }^{17}$

The medical questions included one that asked whether asthma had ever been diagnosed by a physician. For the purpose of the mortality analysis respondents were considered to be exposed (asthma) or unexposed (no asthma). Those with missing data on asthma were excluded $(\mathrm{n}=861) ; 471 \quad(1.5 \%)$ of the respondents had a diagnosis of asthma and 29 $778(95.7 \%)$ did not. Table 1 shows the age and sex distributions of the asthmatic subjects.

Data on deaths and causes of death were obtained from linkage of the study population to the nationwide Finnish death register using the unique personal identity numbers given to all residents of Finland. Thereafter, all deaths that occurred among the study population from 1 January 1976 to 31 December 1991 were classified as being due to all causes, all natural causes, chronic obstructive pulmonary disease (COPD) (ICD 8 codes 490-493), lung cancer 
Table 1 Number of cases and prevalence (\%) of asthma by age in 14654 men and 15595 women

\begin{tabular}{lcllll}
\hline & \multicolumn{2}{c}{ Men } & & \multicolumn{2}{c}{ Women } \\
\cline { 2 - 3 } Age & No. & Prevalence & & No. & Prevalence \\
\hline $18-29$ & 59 & 0.89 & & 49 & 0.71 \\
$30-39$ & 33 & 0.99 & & 35 & 1.11 \\
$40-49$ & 31 & 1.36 & & 44 & 1.99 \\
$50-59$ & 52 & 3.82 & & 58 & 3.46 \\
$60-69$ & 32 & 3.97 & & 44 & 3.68 \\
$70+$ & 10 & 4.74 & & 24 & 4.97 \\
All ages & 217 & 1.48 & 254 & 1.63 \\
\hline
\end{tabular}

(ICD 8 code 162), and natural causes other than COPD or lung cancer. All cases of cancer registered in the national Finnish Cancer Registry were also linked to identify primary lung cancers for the corresponding time period.

Respondents were classified with respect to cigarette smoking as never smokers if they had never smoked more than 10 packs of cigarettes in their lifetime and occasional smokers if they had smoked more than this but had never smoked on a daily or almost daily basis. Regular (daily) smokers were classified as current smokers if they smoked at the time of the questionnaire study and as former smokers if they had stopped smoking. The number of cigarettes smoked daily was asked of regular smokers, separately for former and current smokers.

Six social class groups were defined using the 1970 Finnish census classification based on occupation ${ }^{18}$ : upper level and lower level white collar workers, skilled and unskilled blue collar workers, farmers, and unclassified (students, conscripts, etc). All participants were asked if there were any animals, especially a dog, in their household.

Chronic bronchitis and dyspnoea were assessed by a mailed questionnaire adapted from the London School of Hygiene respiratory questionnaire. ${ }^{19}$ Chronic bronchitis was classified into the following categories: no cough or cough for less than three months per year, cough for more than three months per year, and cough with phlegm for more than three months per year. Dyspnoea was classified into five categories (grades 0-4) depending on the

Table 2 Distributions of age adjusted proportions of potential confounding factors among asthmatic and non-asthmatic men and women

\begin{tabular}{|c|c|c|c|c|}
\hline & \multicolumn{2}{|l|}{ Men } & \multicolumn{2}{|l|}{ Women } \\
\hline & No asthma & Asthma & No asthma & Asthma \\
\hline Hay fever & $6.0 \%$ & $40.5 \%$ & $7.2 \%$ & $47.2 \%$ \\
\hline History of chronic bronchitis ${ }^{1}$ & $4.4 \%$ & $29.7 \%$ & $5.1 \%$ & $29.5 \%$ \\
\hline Symptoms of chronic bronchitis ${ }^{2}$ & $5.1 \%$ & $19.9 \%$ & $4.1 \%$ & $19.6 \%$ \\
\hline Dyspnoea $^{3}$ & $6.3 \%$ & $34.8 \%$ & $9.0 \%$ & $43.4 \%$ \\
\hline \multicolumn{5}{|l|}{ Smoking } \\
\hline Current & $41.6 \%$ & $45.0 \%$ & $22.9 \%$ & $26.5 \%$ \\
\hline Ever smokers & $65.0 \%$ & $69.0 \%$ & $33.4 \%$ & $37.7 \%$ \\
\hline \multicolumn{5}{|l|}{ Smoking years (mean) } \\
\hline Current smokers & 15.9 & 16.2 & 10.3 & 10.5 \\
\hline Ex-smokers & 13.9 & 13.9 & 7.4 & 7.2 \\
\hline \multicolumn{5}{|l|}{ Pack years (mean) } \\
\hline Current smokers & 14.2 & 12.0 & 6.2 & 6.4 \\
\hline Ex-smokers & 11.8 & 9.8 & 3.4 & 3.1 \\
\hline \multicolumn{5}{|l|}{ Occupation } \\
\hline Farmers & $9.5 \%$ & $8.2 \%$ & $10.2 \%$ & $9.0 \%$ \\
\hline Blue collar workers ${ }^{4}$ & $56.0 \%$ & $58.1 \%$ & $42.3 \%$ & $46.1 \%$ \\
\hline Domestic or pet animals & $41.0 \%$ & $34.6 \%$ & $38.1 \%$ & $34.6 \%$ \\
\hline
\end{tabular}

${ }^{1}$ Chronic bronchitis diagnosed by physician.

${ }^{2}$ Cough and phlegm for more than three months per year.

Dyspnoea grade 2,3 or 4 .

${ }^{4}$ Both skilled and unskilled workers. subjects' responses to a question on whether or not they became short of breath while performing different physical activities. ${ }^{19} \mathrm{~A}$ history of hay fever or chronic bronchitis diagnosed by a physician was recorded as present or absent. Table 2 shows the distributions of potential confounding factors among subjects with and without asthma.

ANALYSIS OF DATA

Crude death rates were computed by sex for both exposed and unexposed cohorts. Multivariable analyses were performed using the proportional hazards regression mode ${ }^{20}$ for all subjects. Hazard ratios were computed as the antilogarithm of model regression coefficients $(\beta)$. Confidence intervals were computed based on the standard errors of $\beta$. Because the sample included twin pairs in which both twins were included in the analysis, twins in such pairs could not be considered fully independent observations. To be conservative, the model standard errors were multiplied by the ratio of the square root of the total number of subjects to the square root of the number of subjects who were unrelated - that is, excluding those twins whose cotwin was already included. Finally, 95\% confidence intervals were computed as antilog $(\beta \pm 1.96 \mathrm{SE}(\beta))$. Such confidence intervals are wider and hence more conservative than those obtained directly from the modelling results, and slightly overcorrect for twinship as twins in a pair are neither fully concordant for asthma or mortality. Analyses in which twinship was taken into account are considered below. Analyses were controlled first for age and smoking, then for age, smoking and "social confounders" - that is, social class, domestic animals and pets, dogs - and thirdly for age, smoking, social confounders and "medical confounders" - that is, chronic bronchitis, hay fever, dyspnoea. All analyses were carried out stratifying on 10-year age groups.

Because a substantial proportion of the subjects in this study were twins, twin pairs discordant for asthma were identified to examine whether the mortality of patients with asthma differed from the mortality of their age matched siblings (either monozygotic or dizygotic cotwins). These cotwins represent persons who have generally shared the same childhood environment as the exposed (asthma) subject, and share part or all of their genes by descent in common. An estimate of relative risk was calculated from the ratio of the number of pairs in which the exposed twin, but not the unexposed cotwin, had suffered the outcome of interest to the number of pairs in which the opposite had occurred; standard errors and confidence intervals were also computed. Kalbfleisch and Prentice ${ }^{20}$ have shown that these are unbiased estimators of relative risk.

All statistical analyses were carried out with the SAS and EPICURE program packages.

\section{Results}

The prevalence of asthma in our study population was $1.5 \%$. Age and sex specific pre- 
Table 3 Number of deaths among asthmatic and non-asthmatic men and adjusted hazard ratios (95\% CI) for asthmatic men

\begin{tabular}{|c|c|c|c|c|c|}
\hline \multirow[b]{2}{*}{ Cause of death } & \multirow{2}{*}{$\begin{array}{l}\text { No. of deaths } \\
\text { (asthmatic/non- } \\
\text { asthmatic) }\end{array}$} & \multicolumn{4}{|c|}{ Hazard ratios adjusted for } \\
\hline & & Age & Age + smoking & $\begin{array}{l}+ \text { social }^{2} \\
\text { confounders }\end{array}$ & $\begin{array}{l}+ \text { medical }^{3} \\
\text { confounders }\end{array}$ \\
\hline All causes & $64 / 1693$ & $\begin{array}{l}1.49 \\
(1.09 \text { to } 2.05)\end{array}$ & $\begin{array}{l}1.44 \\
(1.04 \text { to } 1.99)\end{array}$ & $\begin{array}{l}1.39 \\
(1.00 \text { to } 1.95)\end{array}$ & $\begin{array}{l}0.92 \\
(0.63 \text { to } 1.33)\end{array}$ \\
\hline All natural causes & $61 / 1394$ & $\begin{array}{l}1.59 \\
(1.14 \text { to } 2.20)\end{array}$ & $\begin{array}{l}1.52 \\
(1.09 \text { to } 2.12)\end{array}$ & $\begin{array}{l}1.48 \\
(1.05 \text { to } 2.10)\end{array}$ & $\begin{array}{l}0.97 \\
(0.66 \text { to } 1.43)\end{array}$ \\
\hline COPD & $12 / 43$ & $\begin{array}{l}9.34 \\
(4.11 \text { to } 21.22)\end{array}$ & $\begin{array}{l}9.41 \\
(4.12 \text { to } 21.50)\end{array}$ & $\begin{array}{l}10.00 \\
(4.28 \text { to } 23.34)\end{array}$ & $\begin{array}{l}2.09 \\
(0.72 \text { to } 6.02)\end{array}$ \\
\hline Lung cancer & $11 / 104$ & $\begin{array}{l}3.51 \\
(1.59 \text { to } 7.76)\end{array}$ & $\begin{array}{l}3.19 \\
(1.39 \text { to } 7.31)\end{array}$ & $\begin{array}{l}2.81 \\
(1.16 \text { to } 6.78)\end{array}$ & $\begin{array}{l}2.36 \\
(0.88 \text { to } 6.34)\end{array}$ \\
\hline Other $^{1}$ & $38 / 1247$ & $\begin{array}{l}1.12 \\
(0.74 \text { to } 1.68)\end{array}$ & $\begin{array}{l}1.07 \\
(0.70 \text { to } 1.63)\end{array}$ & $\begin{array}{l}1.03 \\
(0.66 \text { to } 1.60)\end{array}$ & $\begin{array}{l}0.70 \\
(0.43 \text { to } 1.14)\end{array}$ \\
\hline
\end{tabular}

${ }^{1}$ Other natural causes than chronic obstructive pulmonary disease or lung cancer.

${ }^{2}$ Age, smoking, social class, pets and dogs.

Age, smoking, social class, pets, dogs, chronic bronchitis, dyspnoea, hay fever.

$\mathrm{COPD}=$ chronic obstructive pulmonary disease.

valences are given in table 1 . This study was directed at adult patients with asthma, initially aged 18 years or more. The study population was young with $68 \%$ of men and $64 \%$ of women being initially under 40 years.

Of the possible confounding factors dyspnoea, chronic bronchitis, and hay fever were significantly more common among subjects with asthma ( $\mathrm{p}<0.001$, table 2$)$. The only significant difference in smoking habits was seen in the pack years smoked by currently smoking men, with non-asthmatic men having smoked more than asthmatic men $(\mathrm{p}=0.02)$. Occupational status was similar in both groups. Non-asthmatic men had somewhat more domestic animals or pets than asthmatic men, but the difference was not significant $(\mathrm{p}=0.06)$. Current smoking and dyspnoea were the only confounders that had a significant effect on the risk of death due to natural causes in this sample.

Table 3 shows the mortality from selected causes for exposed and non-exposed groups

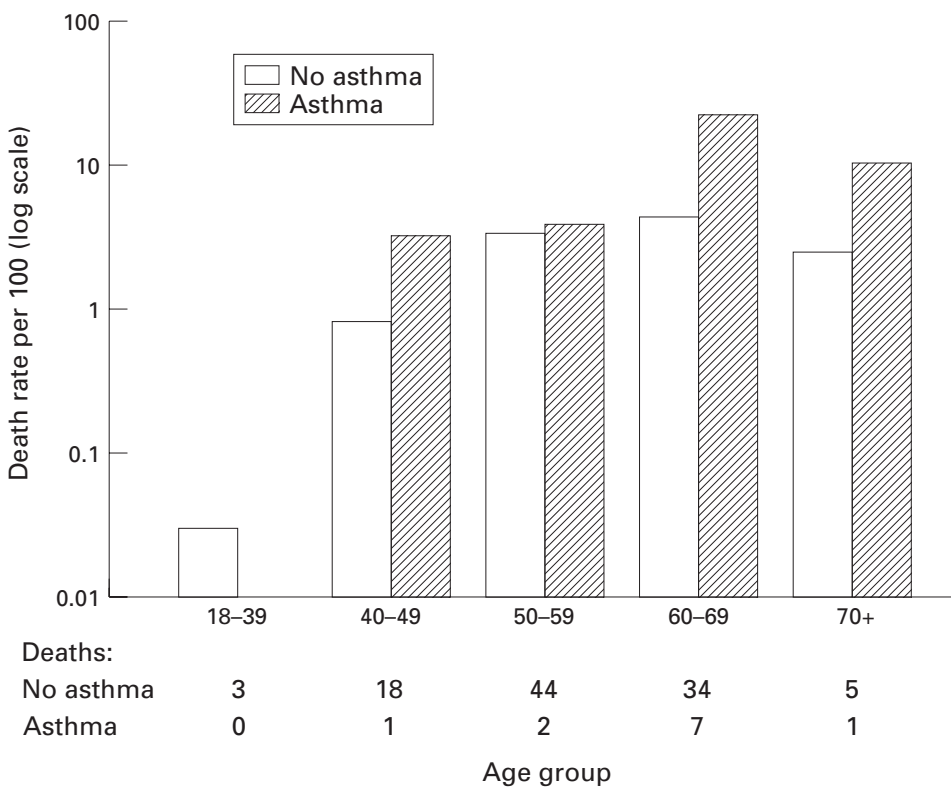

Figure 1 Lung cancer death rates among men with and without asthma by age group (Finnish twin cohort data). Age adjusted Mantel-Haenzel relative risk (RR) estimates = 3.02 (95\% CI 1.67 to 5.43); age and smoking adjusted Mantel-Haenzel RR=2.82 (95\% CI 1.50 to 5.30); Breslow-Day tests for homogeneity of RR values non-significant. of men. The mortality from all causes was increased in asthmatic men, the age adjusted hazard ratio being 1.49 (95\% CI 1.09 to 2.05). No significant interaction was seen between age and the risk effects of asthma, although asthmatic subjects under 40 years did not have increased mortality. When smoking was included the hazard ratio still remained significant, being 1.44 (95\% CI 1.04 to 1.99 ). After adjusting for chronic bronchitis, dyspnoea, and hay fever the overall mortality was not increased further in asthmatic men (adjusted hazard ratio $=0.92,95 \%$ CI 0.63 to 1.33). The same pattern of hazard ratios was seen in the risks of death due to natural causes and those due to COPD. Although the risk of death due to COPD was 10 times higher for asthmatic men, when the effect of social confounders was taken into account there was no significant increase in the risk if the respiratory symptoms were also included. For men with symptoms of chronic bronchitis the relative risk of death due to COPD was 2.25 (95\% CI 0.83 to 6.11 ), and for men in the most severe dyspnoea category the relative risk was 12.0 (95\% CI 3.06 to 47.4 ).

The risk of death due to lung cancer was significantly increased in asthmatic patients after adjusting for age, smoking, and social confounders with a hazard ratio of $2.81(95 \%$ CI 1.16 to 6.78 ). Mortality from lung cancer was also calculated in 10 year age groups (fig 1) and was found to be higher in men with asthma in each age group. When pack years were taken into account the risk of death due to lung cancer was still almost three times higher in asthmatic men. We also looked at the cases of lung cancer on the Finnish Cancer Registry to confirm the diagnoses on the death certificates. There was only one case in which the cause of death on the death certificate was lung cancer but it was not found in the Cancer Registry. The significant effect of smoking on the risk of lung cancer was clearly seen with the risk of death due to lung cancer 19 times higher for current smokers than for nonsmokers (95\% CI 5.34 to 70.0), and for exsmokers the risk ratio was 4.53 (1.18 to 17.4 ) compared with non-smokers.

The results were mostly the same for women and men, although the relative risks were higher among asthmatic women than asthmatic men 
Table 4 Number of deaths among asthmatic and non-asthmatic women and adjusted hazard ratios (95\% CI) for asthmatic women

\begin{tabular}{|c|c|c|c|c|c|}
\hline \multirow[b]{2}{*}{ Cause of death } & \multirow{2}{*}{$\begin{array}{l}\text { No. of deaths } \\
\text { (asthmatic/non- } \\
\text { asthmatic) }\end{array}$} & \multicolumn{4}{|c|}{ Hazard ratios adjusted for } \\
\hline & & Age & Age + smoking & $\begin{array}{l}+ \text { social }^{2} \\
\text { confounders }\end{array}$ & $\begin{array}{l}+ \text { medical }^{3} \\
\text { confounders }\end{array}$ \\
\hline All causes & $59 / 1199$ & $\begin{array}{l}1.53 \\
(1.10 \text { to } 2.13)\end{array}$ & $\begin{array}{l}1.52 \\
(1.09 \text { to } 2.13)\end{array}$ & 1.50 & $\begin{array}{l}1.31 \\
(0.90 \text { to } 1.91)\end{array}$ \\
\hline All natural causes & $58 / 1114$ & $\begin{array}{l}1.59 \\
(1.13 \text { to } 2.22)\end{array}$ & $\begin{array}{l}1.58 \\
(1.12 \text { to } 2.21)\end{array}$ & $\begin{array}{l}1.56 \\
(1.11 \text { to } 2.18)\end{array}$ & $\begin{array}{l}1.38 \\
(0.94 \text { to } 2.01)\end{array}$ \\
\hline COPD & $7 / 9$ & $\begin{array}{l}21.37 \\
(6.05 \text { to } 75.44)\end{array}$ & $\begin{array}{l}19.97 \\
\text { (5.63 to } 70.74)\end{array}$ & $\begin{array}{l}17.67 \\
(4.83 \text { to } 64.67)\end{array}$ & $\begin{array}{l}16.42 \\
(2.84 \text { to } 95.08)\end{array}$ \\
\hline Other $^{1}$ & $50 / 1093$ & $\begin{array}{l}1.39 \\
(0.97 \text { to } 2.00)\end{array}$ & $\begin{array}{l}1.39 \\
(0.96 \text { to } 2.00)\end{array}$ & $\begin{array}{l}1.37 \\
(0.95 \text { to } 1.97)\end{array}$ & $\begin{array}{l}1.22 \\
(0.81 \text { to } 1.83)\end{array}$ \\
\hline
\end{tabular}

${ }^{1}$ Other natural causes than chronic obstructive pulmonary disease or lung cancer.

${ }^{2}$ Age, smoking, social class, pets and dogs.
${ }^{3}$ Age, smoking, social class, pets, dogs, chronic bronchitis, dyspnoea and hay fever.

$\mathrm{COPD}=$ chronic obstructive pulmonary disease.

(table 4). The overall mortality was raised in asthmatic women (age adjusted hazard ratio $1.53,95 \%$ CI 1.10 to 2.13 ). The increased risk remained significant when smoking and other social variables were included. In contrast to the results in men, the increased mortality from COPD in asthmatic women remained significant after adjusting for all confounders (adjusted hazard ratio 16.42 , 95\% CI 2.84 to 95.08). However, the number of deaths was quite small in this group and confidence limits were therefore wide. It was not possible to estimate the risk of death due to lung cancer because there was only one case among asthmatic women.

Asthma was reported as the underlying cause of death in 12 deaths during follow up, 11 of whom had reported asthma in the questionnaire. The sensitivity of the questionnaire self-report to identify future asthma deaths was thus $92 \%$ and the specificity $98 \%$. The risk of death due to causes other than COPD and lung cancer was similar among asthmatic and non-asthmatic subjects.

A total of 861 subjects (463 men) did not answer the question concerning asthma, but the mortality of these men was similar to the remainder of the men in the study population (age adjusted hazard ratio $1.16,95 \%$ CI 0.88 to 1.52 ). The 398 women with no data on asthma had a slightly increased mortality but, after adjusting for age, smoking, and social class, there was no significant difference between them and the remainder of the women in the study (adjusted hazard ratio 1.29, 95\% CI 0.85 to 1.96 ).

The distribution of outcomes for the 293 asthma discordant pairs of twins was consistent with the results of the whole cohort. The overall relative risk for death during follow up was 1.64 (95\% CI 0.97 to 2.81 ), being higher for women than for men. There were 11 deaths from COPD in the asthmatic cotwins compared with two in their non-asthmatic cotwins (relative risk $5.5,95 \%$ CI 1.20 to 51.0 ). A relative risk of 1.8 (0.54 to 6.84) for lung cancer was based on nine and five pairs, respectively.

The distribution of potential confounders was also considered for the asthma discordant twins. Smoking and occupation did not differ. A history of hay fever was found more often in the asthmatic cotwins (relative risk 8.2, 95\% CI 4.57 to 15.8 ), as were other respiratory symptoms (chronic bronchitis 4.4 (95\% CI 2.18 to 9.80 ) and dyspnoea 24 (95\% CI 3.91 to 96.3$)$ ).

\section{Discussion}

The prevalence of asthma in our study was $1.5 \%$ in 1975 , which corresponds to that found in previous studies of adults in Finland. ${ }^{2122} \mathrm{We}$ used a questionnaire based classification of physician diagnosed asthma. Edfors-Lubs found a good agreement between questionnaire and clinical diagnosis in her questionnaire study on allergy in 7000 twin pairs in Sweden. ${ }^{23}$ Vesterinen et $a l^{22}$ examined the validity of self reporting of asthma and found that most of those who reported asthma in a questionnaire given in 1981 had not been admitted to hospital between 1972 and 1983. Of those who had been in hospital because of asthma before the questionnaire study in $1981,75 \%$ reported asthma. ${ }^{22}$ Thus, it seems that in our study the number of subjects with a diagnosis of asthma might also have been underestimated. We did not determine when the asthma diagnosis was made or if asthma was active or asymptomatic at the time of the questionnaire. Longitudinal epidemiological studies have shown that the natural history of asthma includes phases of long lasting remission and even recovery in some cases. ${ }^{24}$ In the follow up study by Vesterinen et al $31.5 \%$ of those who reported asthma no longer reported it after six years. ${ }^{22}$ Isoaho et al found that current asthma accounted for only about $40 \%$ of the cumulative self-reported prevalence in both sexes. ${ }^{25}$ However, despite misclassification errors in both directions the questionnaire based diagnosis of asthma can be considered adequate for assessing mortality rates and, in particular, it was both sensitive and specific as a predictor of asthma deaths.

Several studies of asthma mortality have compared asthmatic patients with standard mortality rates of the population of the study area or with the national death rates. ${ }^{5-7}$ Current smokers were partly excluded from the asthmatic cohort in the study of Silverstein et al while, in contrast, $75 \%$ of the asthmatic group studied by Almind et al were smokers. ${ }^{5}$ Smoking habits were similar in the two groups in our study (table 2). We have no information on asthma medication use in our study, so the 
potential effects of $\beta$ agonists on mortality cannot be taken into account. However, it is likely that these effects are seen in the deaths due to asthma or other chronic obstructive pulmonary diseases. ${ }^{26}$ Even though asthma has a strong genetic component, ${ }^{2728}$ the disease was also associated with an increased mortality risk compared with that of twin brothers and sisters. The risk ratios for the nested case control study corresponded to those found in the whole cohort and thus confirm our results on the individual cases.

The mortality rates from all causes in the present study are similar to those previously reported. ${ }^{24-6}$ Markowe et al matched the cases and controls for age, sex, and practice in their case control study and found increased mortality from all causes with a relative risk of $1.61{ }^{4}$ In our study the risk ratio was 1.49 for men and 1.53 for women when adjusted only for age. However, no difference was seen after chronic bronchitis, dyspnoea, and hay fever were taken into account. These respiratory and allergic symptoms are not pure confounders, but they also carry information on the severity or nature of the disease. Silverstein et al found that patients of 35 years or older who had asthma associated with chronic obstructive pulmonary disease had a worse than expected survival $^{2}$ with differences between the risks in men and women. The higher rate of smoking among men contributes to their higher age specific mortality rates from all causes. Thus, the effect of other injurious factors such as asthma may be more obvious among women. The same sex difference was also seen in the study of Markowe et $a l .{ }^{4}$ In contrast, Almind et al found significantly increased mortality among asthmatic men but not asthmatic women, which may be due to the large proportion of smokers in their study. ${ }^{5}$

The excess of deaths due to COPD was found in asthmatic patients in both sexes; $8.9 \%$ of all deaths among subjects with asthma were assigned an underlying cause of asthma, which may reflect the relatively young age structure of the cohort. Silverstein et al found that asthma was the cause of death in $4 \%$ of the patients who died ${ }^{2}$ and Markowe et al found that only $1 \%$ of the total asthmatic cohort died from asthma over the follow up period. ${ }^{4}$ It is obvious that some of the excess deaths due to COPD are caused by chronic bronchitis or emphysema. There might be some misclassification between asthma and chronic bronchitis, but patients with asthma often also have chronic bronchitis (table 2). The risk of death due to COPD was 2.25-fold for men with chronic bronchitis. It is interesting that it is near the risk of asthmatic men (adjusted relative risk 2.09), while the risk of asthmatic women was much higher (16.42) (tables 3 and 4).

We found asthma to be a risk factor for deaths from lung cancer even when smoking was taken into account as a confounder, though we studied the deaths caused by lung cancer only among men (a total of 11 among asthmatic subjects) because of the small number of cases among women. Our results correspond to previous findings. ${ }^{12-14}$ In our study the mortality risk ratio for asthmatic men was 3.19 (95\% CI 1.39 to 7.31 ) when adjusted for smoking, which is consistent with, though somewhat higher than, the standardised incidence ratio, unadjusted for smoking, of 1.32 (95\% CI 1.22 to 1.42) among 35126 asthmatic men studied by Vesterinen et al. ${ }^{12} \mathrm{Wu}$ et al studied non-smoking women and found that a history of asthma was associated with a significantly increased risk of lung cancer. ${ }^{13}$ In the study of Alavanja et al lifetime non-smoking women who had lung cancer were significantly more likely than controls to have a history of asthma, but the same association was not observed in former smokers. ${ }^{14}$ These increased risks associated with asthma may be due to the inflamed bronchial mucosa being more sensitive to carcinogens combined with higher rates of cell regeneration in inflamed tissues as discussed earlier. $^{12}$

Smoking habits and social class did not fully explain the excess mortality of asthmatic subjects. It would also appear that the factors that increase the risk of death among subjects with asthma are not shared (genetically or in the family environment) with close relatives. Attention to other general health risk factors, in addition to optimal care of asthma itself, may be important for increasing the life expectancy of adult asthmatic patients.

1 Jackson R, Sears MR, Beaglehole R, Rea HH. International trends in asthma mortality: 1970 to 1985 . Chest 1988;94: 914-9.

2 Silverstein MD, Reed CE, O'Connell EJ, Melton LJ III, $\mathrm{O}^{\prime}$ Fallon WM, Yunginger JW. Long-term survival of a cohort of community residents with asthma. $N$ Engl f Med 1994;331:1537-41.

3 McWhorter WP, Polis MA, Kaslow RA. Occurrence, predictors, and consequences of adult asthma in NHANES I and follow-up survey. Am Rev Respir Dis 1989;139. $721-4$.

4 Markowe HLJ, Bulpitt CJ, Shipley MJ, Rose G, Crombie DL, Fleming DM. Prognosis in adult asthma: a national study. BMF 1987;295:949-52.

5 Almind M, Viskum K, Evald T, Dirksen A, Kok-Jensen A A seven-year follow-up study of 343 adults with bronchial asthma. Dan Med Bull 1992;39:561-5.

6 Alderson M, Loy RM. Mortality from respiratory disease at follow-up of patients with asthma. Br F Dis Chest 1977 71:198-202.

7 Robinette CD, Fraumeni JF Jr. Asthma and subsequent mortality in world war II veterans. F Chronic Dis 1978;31 619-24.

8 Mills PK, Beeson WL, Fraser GE, Phillips RL. Allergy and cancer: organ site-specific results from the adventist health cancer: organ site-specific results from the

9 Eriksson NE, Holmen A, Hogstedt B, Mikoczy Z, Hagmar L. A prospective study of cancer incidence in a cohort L. A prospective study of cancer incidence

10 Alderson $M$. Mortality from malignant disease in patients with asthma. Lancet 1974; ii:1475-7.

11 Osann KE. Lung cancer in women: the importance of smoking, family history of cancer, and medical history of respiratory disease. Cancer Res 1991;51:4893-7.

12 Vesterinen E, Pukkala E, Timonen T, Aromaa A. Cancer incidence among 78000 asthmatic patients. Int $\mathcal{F}$ Epidemiol 1993;22:976-82.

13 Wu AH, Fontham ETH, Reynolds P, Greenberg RS, Buffler $\mathrm{P}$, Liff J, et al. Previous lung disease and risk of lung cancer among lifetime nonsmoking women in the United States. Am f Epidemiol 1995;141:1023-32.

14 Alavanja MCR, Brownson RC, Boice JD Jr, Hock E. Preexisting lung disease and lung cancer among nonsmoking women. Am f Epidemiol 1992;136:623-32.

15 Toren K, Horte L-G, Jarvholm B. Occupation and smoking adjusted mortality due to asthma among Swedish men. adjusted mortality due to asth

16 Kaprio J, Sarna S, Koskenvuo M, Rantasalo I. The Finnish Twin Registry: formation and compilation, questionnaire study, zygosity determination procedures, and research study, zygosity determination procedures, and research
program. In: Nance WE, ed. Twin research: biology and epidemiology. New York: Alan R Liss, 1978:179-84.

17 Sarna S, Kaprio J, Sistonen P, Koskenvuo M. Diagnosis of twin zygosity by mailed questionnaire. Hum Hered 1978 28:241-54.

18 Central Statistical Office of Finland. Census 1970, Part 9: Occupation and social class. Helsinki: Central Statistical Office of Finland, 1974: 490-1. 
19 Rose GA, Blackburn H. Cardiovascular survey methods. World Health Organization Monograph Series No 56. Geneva: WHO, 1968

20 Kalbfleisch JD, Prentice RL. The statistical analysis of failure time data. New York: John .Wiley, 1980: 70-118.

21 Haahtela T, Lindholm H, Bjorksten F, Koskenvuo K, Laitinen LA. Prevalence of asthma in Finnish young men. tinen LA. 1990;301:266-8.

22 Vesterinen E, Kaprio J, Koskenvuo M. Prospective study of asthma in relation to smoking habits among 14729 adults. Thorax 1988;43:534-9.

23 Edfors-Lubs M-L. Allergy in 7000 twin pairs. Acta Allergol 1971;26:249-85.
24 Bronniman S, Burrows B. A prospective study of the natura history of asthma. Remission and relapse rates. Chest 1986 90:480-4.

25 Isoaho R, Puolijoki H, Huhti E, Kivela S-L, Tala E. Prevalence of asthma in elderly Finns. F Clin Epidemiol 1994 47:1109-18.

26 Crane J, Pearce N, Burgess C, Beasley R. Asthma and the beta-agonist debate. Thorax 1995;50(Suppl 1):S5-10.

27 Nieminen MM, Kaprio J, Koskenvuo M. A populationbased study of bronchial asthma in adult twin pairs. Chest 1991;100:70-5.

28 Duffy DL, Martin NG, Battistutta D, Hopper JL, Mathews JD. Genetics of asthma and hay fever in Australian twins. Am Rev Respir Dis 1990;142:1351-8. 